\title{
The NAC domain-containing protein, GmNAC6, is a downstream component of the ER stress- and osmotic stress-induced NRP-mediated cell-death signaling pathway
}

\author{
Jerusa AQA Faria', Pedro AB Reis ${ }^{1,2}$, Marco TB Reis ${ }^{1}$, Gustavo L Rosado ${ }^{1,2}$, Guilherme L Pinheiro', \\ Giselle C Mendes ${ }^{1,2}$ and Elizabeth PB Fontes ${ }^{1,2^{*}}$
}

\begin{abstract}
Background: The endoplasmic reticulum (ER) is a major signaling organelle, which integrates a variety of responses against physiological stresses. In plants, one such stress-integrating response is the N-rich protein (NRP)mediated cell death signaling pathway, which is synergistically activated by combined ER stress and osmotic stress signals. Despite the potential of this integrated signaling to protect plant cells against different stress conditions, mechanistic knowledge of the pathway is lacking, and downstream components have yet to be identified.

Results: In the present investigation, we discovered an NAC domain-containing protein from soybean, GmNAC6 (Glycine max NAC6), to be a downstream component of the integrated pathway. Similar to NRP-A and NRP-B, GmNAC6 is induced by ER stress and osmotic stress individually, but requires both signals for full activation. Transient expression of GmNAC6 promoted cell death and hypersensitive-like responses in planta. GmNAC6 and NRPs also share overlapping responses to biotic signals, but the induction of NRPs peaked before the increased accumulation of GmNAC6 transcripts. Consistent with the delayed kinetics of GmNAC6 induction, increased levels of NRP-A and NRP-B transcripts induced promoter activation and the expression of the GmNAC6 gene.
\end{abstract}

Conclusions: Collectively, our results biochemically link GmNAC6 to the ER stress- and osmotic stress-integrating cell death response and show that GmNAC6 may act downstream of the NRPs.

Keywords: GmNAC6, Cell death, ER stress, osmotic stress, NRPs, N-rich proteins

\section{Background}

Plants do not passively accept abiotic stresses, such as drought, salinity and variations of temperature, or biotic aggressors, such as viruses, bacteria, insects and fungi. To cope with these environmental stressors, plant cells have developed coordinated and integrated molecular networks for stress signal perception, transduction and adaptation mechanisms under adverse conditions of growth. In general, some adaptive cellular responses to a specific stress condition are interconnected with other environmental responses [1-3]. For instance, conditions

\footnotetext{
* Correspondence: bbfontes@ufv.br

'Departamento de Bioquímica e Biologia Molecular/BIOAGRO, Universidade Federal de Viçosa, 36570.000, Viçosa, Minas Gerais, Brazil

Full list of author information is available at the end of the article
}

of water stress result in both nutritional and osmotic stress, which can also be caused by salt stress. Similarly, increasing evidence in the literature has demonstrated the interconnection among the responses to pathogen attack and developmental signals [4-6]. In this complex interplay of physiological stresses, plant cells have evolved both anterograde and retrograde transduction pathways among the organelles to respond to environmental signals in an integrated and coordinated manner. One such major signaling organelle is the endoplasmic reticulum (ER), which integrates a variety of responses against stresses $[7,8]$.

The ER is a multifunctional organelle that supports a series of basic cellular processes, such as protein folding and quality control, the maintenance of $\mathrm{Ca}^{2+}$ balance
C Biomed Central

(c) 2011 Faria et al; licensee BioMed Central Ltd. This is an Open Access article distributed under the terms of the Creative Commons Attribution License (http://creativecommons.org/licenses/by/2.0), which permits unrestricted use, distribution, and reproduction in any medium, provided the original work is properly cited. 
and lipid biosynthesis. Any condition that disturbs ER homeostasis and ER function can induce stress in the organelle. In general, ER stress is initiated by an imbalance between the rate of protein synthesis and ER protein-processing activities. Under conditions in which the nascent, unfolded polypeptide influx into the lumen of the ER exceeds the folding and processing capacity of the organelle, unfolded proteins accumulate in the lumen of the ER and, in turn, trigger a cytoprotective pathway designated 'the unfolded protein response (UPR), which has been described in details in mammalian cells [for a review, see [9]]. To alleviate ER stress, the coordinated action of three UPR transducers, activating transcription factor 6 (ATF6), the inositol requiring kinase 1 (IRE1), and double-stranded RNA-activated protein kinase (PKR)-like endoplasmic reticulum kinase (PERK), leads to the activation of the following three types of cellular response: (1) the up-regulation of ER molecular chaperones, such as BiP (binding protein) and calnexin (CNX); (2) the attenuation of protein translation that is mediated by PERK through the phosphorylation of eukaryotic initiation factor $2 \alpha$ (eIF $2 \alpha$ ); and (3) the degradation of misfolded proteins by a process called 'ER-associated degradation' (ERAD). However, excessive or prolonged stress can lead to maladaptive responses and, ultimately, can activate apoptotic cell death to protect tissues from necrotic injury [9]. Recent studies have demonstrated that ER stress can also elicit an innate immunity defense to protect tissues in mammalian cells, and in plant cells, ER stress is linked to the host defense response to microbial infections [10-12]. Thus, in addition to the UPR, other signaling pathways radiate from the ER to the mitochondria, nucleus and possibly other organelles.

Recently, a global expression profiling on tunicamycininduced and polyethylene glycol (PEG)-induced soybean leaves uncovered an ER stress- and osmotic stressshared response represented by co-regulated genes that was found to be synergistically induced by both stresses $[13,14]$. Genes in this integrated pathway encode proteins with diverse roles, such as plant-specific development and cell death (DCD) domain-containing proteins, represented by the asparagine-rich proteins NRP-A and NRP-B, an ubiquitin-associated (UBA) protein homolog and NAC (NAM, ATAF1, ATAF2 and CUC2) domaincontaining proteins. NAC proteins are plant specific transcriptional factors that are involved in a variety of developmental events as well as in biotic and abiotic stress responses [for a review, see [15]]. They comprise a large family of transcriptional regulator genes and, in the soybean genome, are represented by at least 101 sequences [16].

The N-rich protein $(N R P)$ genes, which demonstrated the strongest synergistic induction, share a highly conserved C-terminal DCD domain in addition to a high content of asparagine residues at their more divergent $\mathrm{N}$ termini [13]. This structural organization places NRP-A and NRP-B in the subgroup I of plant-specific DCD-containing proteins [17]. We have recently demonstrated that both NRP-A and NRP-B induce a senescence-like response when ectopically expressed in soybean cells and tobacco leaves [13]. These studies have demonstrated that ER stress and osmotic stress pathways converge at the level of NRP gene activation to potentiate a cell death response. In fact, the combination of both stress signals intensifies the output of the different pathways upon NRP expression; therefore, NRPs serve as molecular links that integrate the ER stress and osmotic stress responses. This ER stress- and osmotic stress-integrating response has been designated as the NRP-mediated cell death signaling, which is synergistically activated by both stress signals. We have recently demonstrated that the transcriptional factor GmERD15 acts upstream of NRPs and activates the expression of NRP-A and NRP-B in response to osmotic stress and ER stress [18]. Although the integrated signaling pathway has the potential to accommodate general plant-specific adaptive responses, mechanistic knowledge of the pathway is lacking, and downstream components have yet to be identified. Here, we describe a member of the NAC domain-containing protein superfamily from soybean, GmNAC6 (Glycine max NAC6) as a possible downstream component of the pathway. In addition to being synergistically up-regulated by a combination of ER stress and osmotic stress signals, ectopic expression of GmNAC6 causes senescence-like responses in planta, a phenotype that resembles the NRP-mediated response. We also found that NRPs induce promoter activation and expression of GmNAC6 genes.

\section{Results}

GmNAC6 is induced by ER stress and osmotic stress individually but requires both signals for full activation

To identify components of the ER stress- and osmotic stress-integrating NRP-mediated cell-death response, we searched among the co-regulated genes by both stresses [14] for those that were synergistically induced by both stress signals. In this regard, we focused our attention on an EST encoding a member of the NAC domaincontaining protein family and extended our search to other members of the soybean NAC protein family. At least three members of the NAC domain-containing protein family from soybean -GmNAC1, GmNAC5 and GmNAC6- have been associated with senescence or cell death [16]. However, only GmNAC6 was induced by the osmotic stress inducer, PEG, and the ER stress-inducing agents, tunicamycin (TUN) and L-azetidine-2-carboxylic acid (AZC), which cause protein misfolding in the ER 
by different mechanisms (Figure 1A). ER stress (BiPD and $C N X)$ and osmotic stress $(S M P)$ marker genes were included in the assay to ensure the efficiency of the tunicamycin and PEG treatments. The combination of ER stress and osmotic stress promoted a slightly more than additive effect on the accumulation of GmNAC6 transcripts in a fashion similar to the induction of the NRP-A and NRP-B genes (Figure 1B). These results indicate that the integration of ER-stress and osmoticstress signals leads to the full activation of GmNAC6.

We also examined the induction of other members of the soybean NAC gene family, such as GmNAC3, which is up-regulated by PEG [16] and tunicamycin (Figure
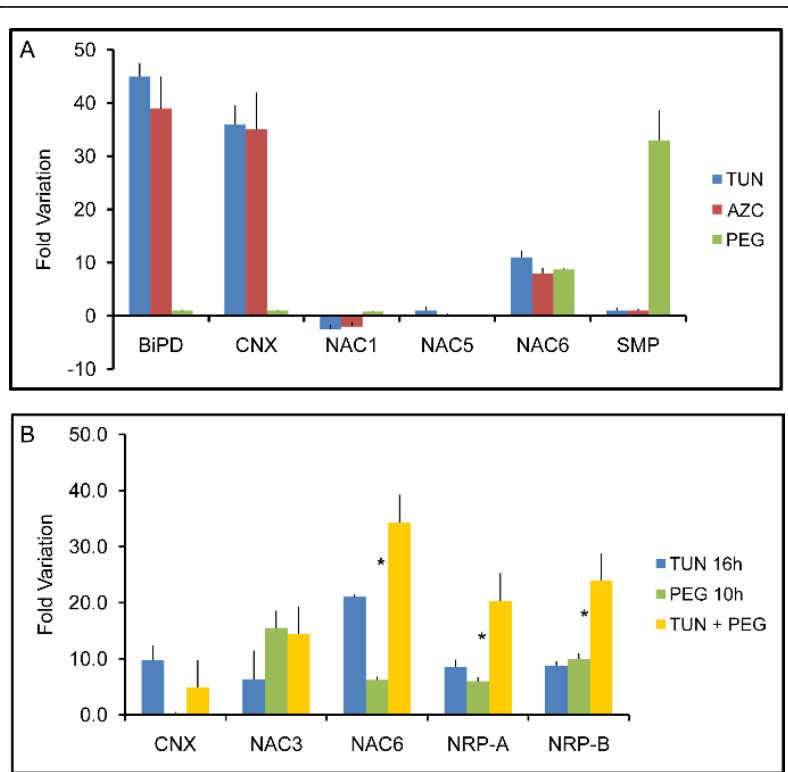

Figure 1 The integration of ER-stress and osmotic-stress signals leads to full activation of GmNAC6. A. The effect of PEG, tunicamycin or AZC on the expression of GmNAC1, GMNAC5 and GmNAC6. Three-week-old plants were treated with tunicamycin TUN $(10 \mu \mathrm{g} / \mathrm{ml}, 24 \mathrm{~h})$, PEG (MW:8000, 10\%, 16 h) or AZC (50 mM, 16 h). The relative expression of representative genes of UPR (BIPD and CNX), osmotic stress-specific response (SMP) and senescenceassociated soybean GmNAC genes (NAC1, NAC5, and NAC6) was determined by quantitative RT-PCR. Values for TUN are relative to the DMSO control treatment, and for PEG and AZC the values are relative to the $\mathrm{H}_{2} \mathrm{O}$ control; values represent the mean \pm SD of three replicates from three independent experiments. B. The synergistic induction of GmNAC6 transcripts by a combination of PEG and tunicamycin treatments. Plants were treated with TUN (16 h) or PEG (10 h) alone or a combination of TUN + PEG. For the combined treatments PEG + TUN, the plants were pre-treated with tunicamycin for $6 \mathrm{~h}$ when PEG was added for an additional $10 \mathrm{~h}$. RNA was isolated after the indicated time and quantified by real time RT-PCR, targeting the UPR-specific gene, CNX, the senescenceassociated soybean genes, GmNAC3 and GmNAC6, and the integrated pathway genes, NRP-A and NRP-B. Asterisks indicate the position of additive responses. $\mathrm{H}_{2} \mathrm{O}$ and DMSO are control treatments for PEG and TUN, respectively. Values represent the mean \pm SD of three replicates from three independent experiments.
1B) as well as during leaf senescence [17]. The combined exposure of soybean seedlings to both stress inducers, however, did not promote an additive or synergistic effect on the induction of GmNAC3. Taken together, these results substantiate the argument that GmNAC6, but not GmNAC3, may be a target of the NRP-mediated cell death signaling that integrates ER stress and osmotic stress responses.

\section{GmNAC6 promotes cell death in tobacco leaves and in soybean cells}

We have recently demonstrated that the integrated pathway transduces a programmed cell death (PCD) signal generated by ER- and osmotic-stresses that results in the appearance of markers associated with leaf senescence [13]. To assess whether GmNA6 is involved in cell death, we assayed for hallmarks of leaf senescence, such as chlorotic lesions, chlorophyll loss, lipid peroxidation and the induction of senescence-associated genes in tobacco leaf sectors infiltrated with Agrobacterium carrying a 35S::GmNAC6 construct. After five days post-infiltration, the leaf sectors expressing GmNAC6 displayed a chlorotic phenotype with necrotic lesions that rapidly evolved to intense necrosis at seven days post-infiltration as a result of massive cell death; this observation was in marked contrast with the expression of an unrelated NIG gene [19] used as a negative control (Figure 2A). We also noticed that the GmNAC6induced chlorotic phenotype appeared more rapidly than that promoted by expression of NRP-B gene (compare Figure $2 \mathrm{~A}$ and Additional file 1). In fact, under similar conditions, the symptoms induced by NRP-B expression were first visible at 8 days post-Agro-infiltration when an increase in membrane ion leakage of the NRP-B Agroinfiltrated leaves was also observed (Additional file $2 \mathrm{~A}$ ).

The expression of GmNAC6 (Figure 2B) promoted chlorophyll loss in the Agroinfiltrated sectors (Figure $2 \mathrm{C}$ ), an increase in membrane ion leakage of Agroinfiltrated leaves (Additional file 2B) and a significant increase in lipid peroxidation (Figure 2D) at five days after infiltration. The latter was examined by measuring the accumulation of thiobarbituric acid (TBA)-reactive compounds, which was clearly enhanced in the $35 \mathrm{~S}:$ : GmNAC6 Agro-inoculated leave sectors, when compared with the leaf slices that were Agro-inoculated with the control 35S::NIG gene. These TBA-reactive compounds are products of senescence-associated lipid peroxidation, a process that results in the generation of reactive oxygen species (ROS) and chlorophyll loss [20].

We further confirmed the GmNAC6-induced senescence-like phenotype by monitoring the expression of the senescence-associated gene markers, NTCP-23 (AB032168, called CP1 in [13], which has been shown 

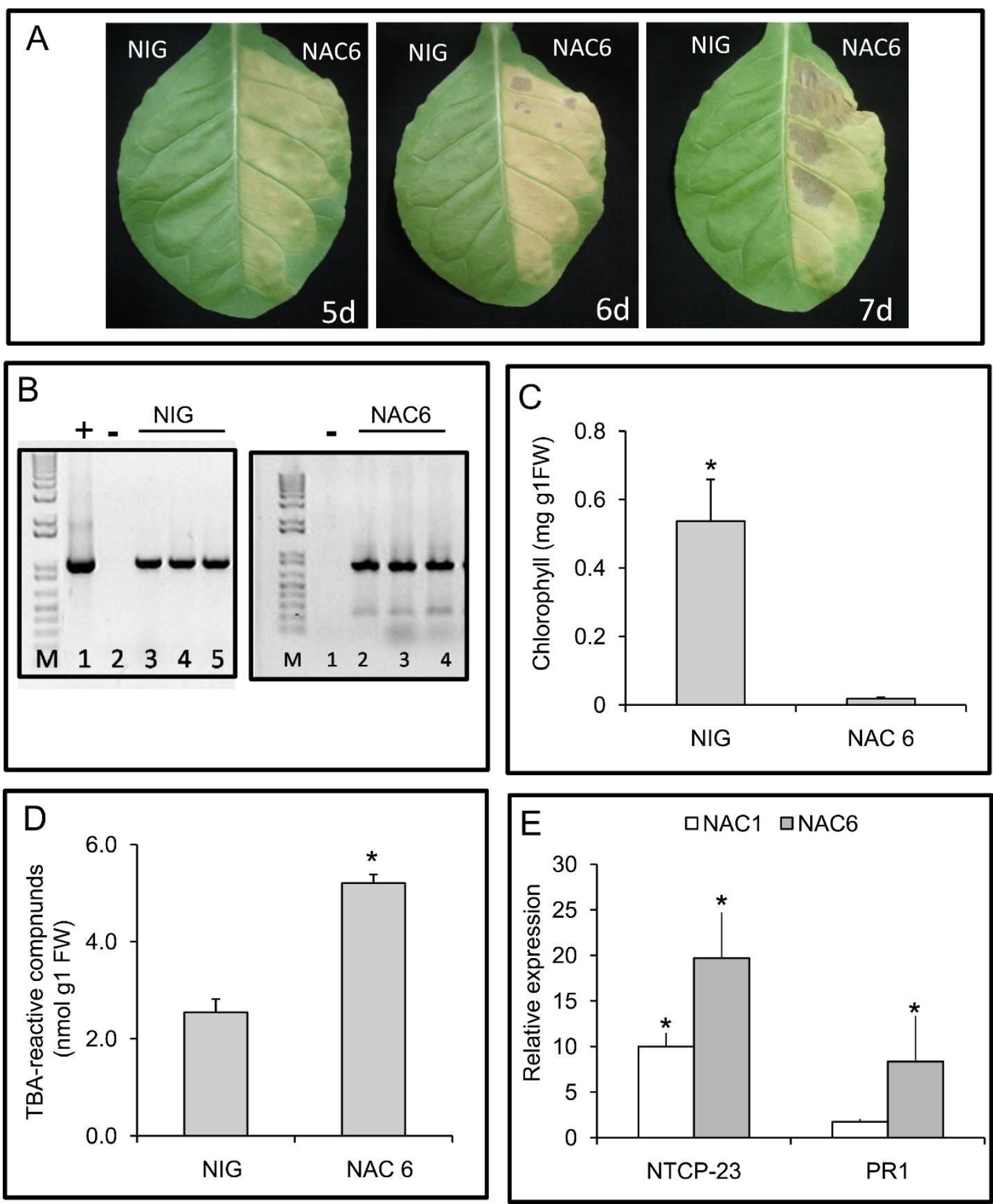

Figure 2 GmNAC6 promotes cell death in planta. A. Three-week-old tobacco leaves were infiltrated with Agrobacterium cells carrying the 35S::YFP-NAC6 construct or an unrelated 35S::NIG construct. A. The yellowing phenotypes and necrotic lesions caused by GmNAC6 expression. Leaf sectors were infiltrated with the indicated Agro-inoculum and photographs were taken at 5 days ( 5 d), 6 days ( 6 d) and 7 days (7 d) postAgro-inoculation. B. Transient expression of NIG and GmNAC6 genes in Agro-infiltrated leaf sectors at 5 days after Agroinfiltration. Semiquantitative RT-PCR was on RNA of Agro-infiltrated leaf sectors with gene-specific primers, as indicated in the figure. C. Chlorophyll loss in the 35S::GmNAC6-infiltrated sectors. Total chlorophyll was determined from the leaf sectors Agro-infiltrated for 5 days with the samples in (A). The values are given as mean \pm SD from three replicates. D. Lipid peroxidation induced by GmNAC6 expression. The lipid peroxidation in the 5-dinfiltrated leaf sectors from (A) was monitored by determining the level of TBA-reactive compounds. The values are given as mean \pm SD from three replicates. Asterisks indicate values significantly different from the control treatment ( $p<0.05$, Tukey HSD test). E. The induction of the senescence-associated gene, NTCP23, and pathogenesis-related gene 1, PR1, by GmNAC6 expression. Total RNA was isolated from 5-dayinfiltrated leaf sectors that were infiltrated with 355::GmNAC6 (gray bars) or 355::GmNAC1 (white bars), and the gene induction was monitored by quantitative RT-PCR using gene-specific primers. Values are relative to the control treatment (NIG infiltration) and asterisks indicate statistic differences ( $p<0.05$, Tukey HSD test). 
to be up-regulated in association with tobacco leaf senescence $[13,21]$, and the pathogenesis-related gene 1 [PR1, [22]], by quantitative RT-PCR. The expression of GmNAC6 promoted an enhanced accumulation of NTCP-23 and PR1 transcripts (Figure 2E). GmNAC1, which has also been shown to be associated with senescence in soybean [16], induced the expression of NPCP23 and, to a much lesser extent, PR1 when transiently expressed in tobacco leaves, demonstrating the effectiveness of the assay in this heterologous system. Taken together, these results indicate that GmNAC6 expression induces a senescence-like response in tobacco leaves.

Because NRPs, effectors of the ER stress and osmotic stress-integrating cell death response, have also been shown to induce cell death when transiently expressed in soybean cells, we examined whether GmNAC6 could induce the activity of caspase 3-like and DNA fragmentation in the endogenous system. The transient expression of GmNAC6 was driven by the $35 \mathrm{~S}$ promoter in soybean protoplasts and was measured by RT-PCR, relative to a helicase marker to control for any variation in the transformation efficiency (Figure 3A). The caspase 3-like activity in total protein extracts from GmNAC6overexpressing soybean cells was 3.62-fold higher than in extracts from protoplasts transformed with the empty vector (Figure 3B). We also used the terminal deoxynucleotidyltransferase-mediated dUTP nick end labeling (TUNEL) technique to measure fragmentation of DNA in individual cells 36 hours post electroporation (Figure 3C). After TUNEL labeling, the fomaldehyde-fixed and permeabilized semi-protoplasted leaf cells were also counterstained with propidium iodide (PI). Under these conditions, PI stained all cells and the red fluorescence signal concentrates in the nucleus as we treated the samples with RNase (Figure 3C, empty vector, see arrows). The nuclei of control cells transformed with the empty vector fluoresced intensely with propidium iodide (PI, red) and exhibited only TUNEL-negative nuclei (panel empty vector). In contrast, the GmNAC6expressing samples had TUNEL positive nuclei that showed the same extent of staining as NRP-B (data not shown) and DNase treated positive controls. Merged is an overlay of the fluorescent image of TUNEL labeling with PI staining cells to facilitate the identification of TUNEL-positive nuclei. From two independent experiments, approximately $21 \% \pm 1.5$ of the semi-protoplasted leaf cells transformed with 35S::GmNAC6 had TUNEL- positive nuclei. Very likely the low efficiency of protoplasts transformation may account for the relatively low percentage of TUNEL positive nuclei in protoplasts electroporated with 35S::GmNAC6. Because caspase 3-like activity and DNA fragmentation have been described as biochemical markers associated with programmed cell death in soybean suspension cells [13], our results are consistent with an involvement of GmNAC6 in cell death events.

\section{NRPs and GmNAC6 are coordinately induced by biotic stresses but with different kinetics}

The activation of the NRP-mediated senescence-like response is not specific to ER stress or osmotic stress but is, rather, a shared branch of general environmental adaptive pathways. In fact, NRPs are also induced by other abiotic and biotic signals, such as drought and pathogenincompatible interactions $[23,24]$. As a putative component of NRP-mediated signaling, we examined whether GmNAC6 is induced by biotic signals as well (Figure 4). We first treated soybean leaves with cell wall-degrading enzymes $(\mathrm{CDE})$, which mimic bacterial pathogen attack and induce a defense response [25], and then we inoculated soybean leaves with the incompatible bacterium, Pseudomonas syringae patovar tomato (Additional file 3), as our experimental system. Levels of GmNAC6 mRNA were examined at various times after treatment with $\mathrm{CDE}$ and inoculation with the bacterial pathogen (Figures 4A and $4 \mathrm{~B}$ ). As positive controls in the CDE treatments, we also examined the expression of the ER-resident molecular chaperones, binding protein $(\mathrm{BiP})$ and calnexin $(\mathrm{CNX})$, which have previously been demonstrated to be induced by CDE [10], and the glutathione-S-transferase (GST) gene that is also co-regulated by ER stress and osmotic stress [14] in the same fashion as NRPs and GmNAC6 (Figure 4A). For assaying the effectiveness of the incompatible bacterium, Pseudomonas syringae patovar tomato, in soybean, we examined the induction of the pathogenesisrelated genes, PR1 and PR4 (Figure 4B). As with the NRPs, both of the treatments promoted the induction of GmNAC6 but with slightly different kinetics. The CDE treatment (Figure 4A) and bacterial inoculation (Figure $4 \mathrm{~B}$ ) resulted in increased NRP-A and NRP-B transcript levels as early as 1 hour and 3 hour, respectively, after the treatments. In contrast to the rapid induction of NRPs, the induction of GmNAC6 occurred with delayed kinetics, similar to the ER-resident chaperones, BiP and CNX, (Figure 4A) and the pathogenesis-related genes, PR1 and PR4 (Figure 4B). The induction of GmNAC6 by the CDE treatment and by the inoculation of the incompatible bacterium was first detected $3 \mathrm{~h}$ after the treatments. The GmNAC6 transcripts reached maximal accumulation at $10 \mathrm{~h}$ after inoculation of the soybean leaves with the incompatible bacterium (Figure 4B). These results indicate that NRP-A and NRP-B induction precedes the increased expression of GmNAC6.

\section{NRP-A and NRP-B induce the expression of the GmNAC6 gene}

The coordinated synergistic induction of GmNAC6 by osmotic stress and ER stress, along with its capacity to 

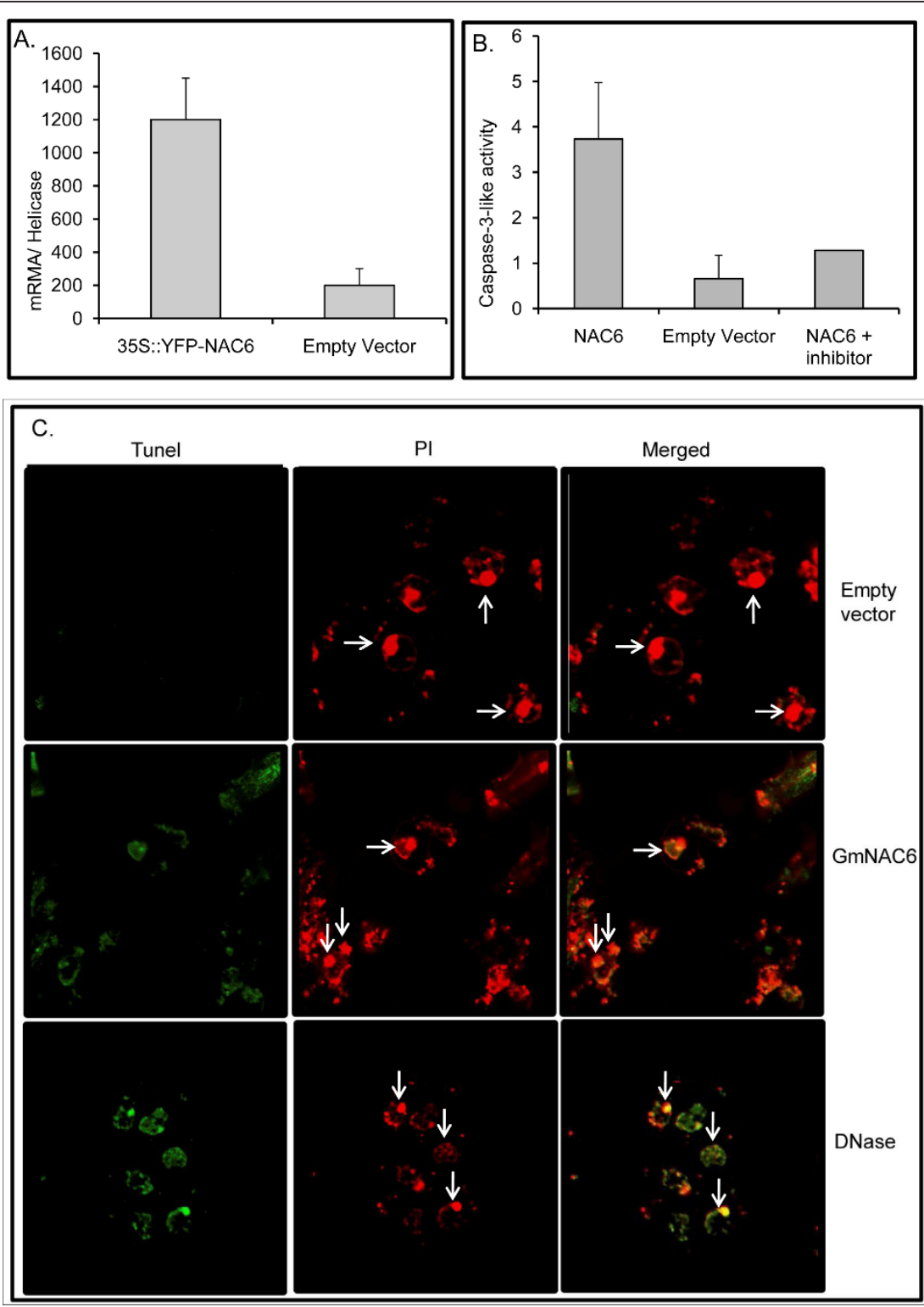

Figure 3 The transient expression of GmNAC6 in leaf soybean protoplasts induces cell death. Transient expression of GmNAC6 in protoplasts. Soybean protoplasts were electroporated with the 35S::YFP-NAC6 construct or the empty vector, and the expression of GmNAC6 and YFP-GmNAC6 was monitored by quantitative RT-PCR 36-h after electroporation. Values of expression were calculated using the $2^{-\Delta C t}$ method and helicase as endogenous control. Values represent the mean \pm SD of three replicates. B. Caspase-3-like activity. Total protein was extracted from GmNAC6-electroporated protoplasts after $36 \mathrm{~h}$, and caspase 3-like activities were monitored with a DEVD-pNA substrate in the absence and presence of a specific inhibitor. Values represent the mean \pm SD of three replicates. C. DNA fragmentation promoted by GmNAC6 expression. Cells were sampled 36-h post-electroporation of soybean protoplasts with empty vector or GMNAC6 expression cassette, submitted to TUNEL labeling and examined by confocal microscopy. The cells were also counterstained with propidium iodide (PI) and examined for red fluorescence at $632 \mathrm{~nm}$. Arrows indicate some nuclei. Merged is an overlay of the fluorescent image of TUNEL labeling with PI staining cells to facilitate the identification of TUNEL-positive nuclei. As a positive control, untransfected cells were also treated with DNase.

promote NRP-like senescence phenotypes and PCD-like responses in plants, linked GmNAC6 to the ER stress and osmotic stress-integrating NRP-mediated signaling. To position GmNAC6 in this pathway, we examined the expression of GmNAC6 and NRPs in response to each other. The genes GmNAC6 (Figure 5A), NRP-A (Figure
$5 C$ ) and $N R P-B$ (Figure 5D) were placed under the control of the $35 \mathrm{~S}$ promoter and overexpressed in soybean protoplasts derived from cultured cells. We first analyzed the kinetics of NRPs and GmNAC6 induction in response to the plant cell wall-degrading enzymes (CDE) used during the protoplasting procedure 


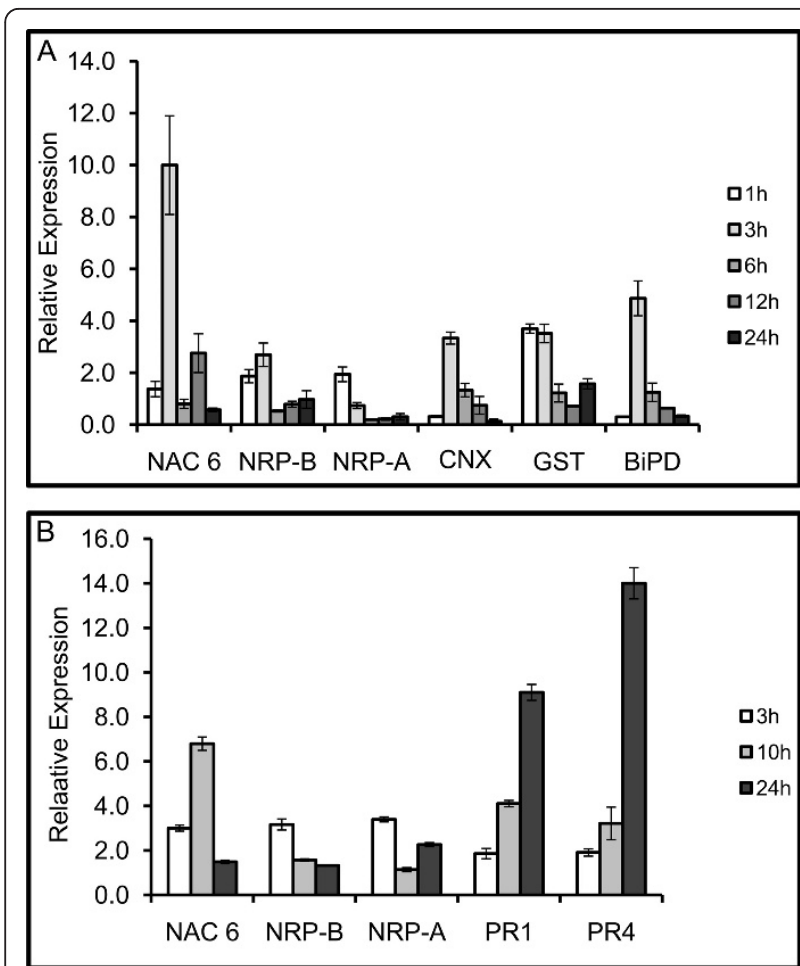

Figure 4 Time course of GmNAC6 induction by biotic stress signals. A. GmNAC6 is induced by treatment with cell walldegrading enzymes (CDE). Soybean leaves were infiltrated with $C D E$, as described in the Methods, for the indicated times. Total RNA was isolated from the infiltrated sectors, and the relative expression of GmNAC6 (NAC6), UPR-specific gene markers (CNX and BiP) and integrated pathway genes (NRP-A, NRP-B, and GST) was determined by quantitative RT-PCR. B. Up-regulation of GmNAC6 by the hypersensitive response. Soybean leaves were inoculated with

Pseudomonas syringae patovar tomato (P.st.) for the indicated period of time. The relative expression of GmNAC6, the integrated pathway genes (NRP-A and NRP-B) and pathogenesis-related genes (PR1 and PR4) was determined by quantitative RT-PCR.

(Additional file 4). NRP-B transcripts were rapidly and transiently induced by $\mathrm{CDE}$ treatment, whereas the kinetics of GmNAC6 induction was delayed. Consistent with the delayed kinetics of the GmNAC6 induction by $\mathrm{CDE}$ treatment and physiological stresses, we found that the transient expression of GmNAC6 in soybean protoplasts did not result in the increased accumulation of $N R P$ transcripts (Figure $5 \mathrm{~B}$ ). In contrast, the transient expression of both NRP-A or NRP-B induced GmNAC6 expression (Figure 5E). The increased accumulation of GmNAC6 transcripts by NRPs was a specific, rather than a general, phenomenon because the transient expression of $N R P-A$ or $N R P-B$ did not promote an upregulation of other members of the soybean NAC domain-containing protein family. These results demonstrate that NRPs can induce GmNAC6, but GmNAC6 cannot induce NRPs.
Transient expression of NRPs activates the GmNAC6 promoter in soybean cells

We next examined whether the observed activation of GmNAC6 by NRPs was at the transcriptional level by a transient expression assay in soybean protoplasts with an NRP-B promoter:: $\beta$-glucuronidase (GUS) reporter construct. In this construct, a 5'-flanking sequence fragment of $N R P-B$ (up to position -1000 , relative to the translational initiation codon) was used to drive GUS expression. Because GmNAC6, NRP-B and NRP-A are transiently induced during the protoplast preparation by CDE (Additional file 4) and wounding [18], we measured the activity of the reporter gene at 36 -h after transfection, when the expression of NRPs returned to basal levels and the accumulation of GUS driven by the CDE- and wounding-induced GmNAC6 promoter was expected to decline to lower levels (see Additional file 4). Under these conditions, the transient expression of $N R P-A$ and $N R P-B$ in soybean protoplasts (Figure 6A) resulted in increased reporter gene expression (Figure $6 \mathrm{~B})$, indicating that the control of GmNAC6 expression by NRP-B and NRP-B occurs, at least in part, at the transcriptional level. We also included the expression of the unrelated NIG gene in the assay as a negative control for specific promoter activation.

\section{Discussion}

In contrast to the UPR, the NRP-mediated cell death signaling pathway is a plant-specific ER-stress celldeath response that communicates with other environmental stimuli through shared components. In fact, osmotic stress also activates the transduction of a cell death signal through NRPs. The convergence of both stress signals on NRP expression in a synergistic manner allows the transfer of information between these two distinct stress response pathways to potentiate a cell death response. Therefore, the integration of the ER stress and osmotic stress signals into a circuit of cell death occurs through the activation of NRPmediated signaling. This cell death integrated pathway has emerged as a relevant adaptive response of plant cells to multiple environmental stimuli. Nevertheless, knowledge about this signaling pathway is limited to the identification of NRP as a crucial mediator of the cell death response and GmERD15 as a transcriptional factor that activates NRPs expression. Here, we describe a member of the NAC domain-containing protein family from soybean, GmNAC6, that may act downstream of NRP-A or NRP-B in the integration of the ER-stress and osmotic-stress cell death signals. GmNAC6 was linked to NRP-mediated cell death signaling based on three criteria. First, we showed that GmNAC6 expression was up-regulated by ER stress and osmotic stress individually, but when combined, 

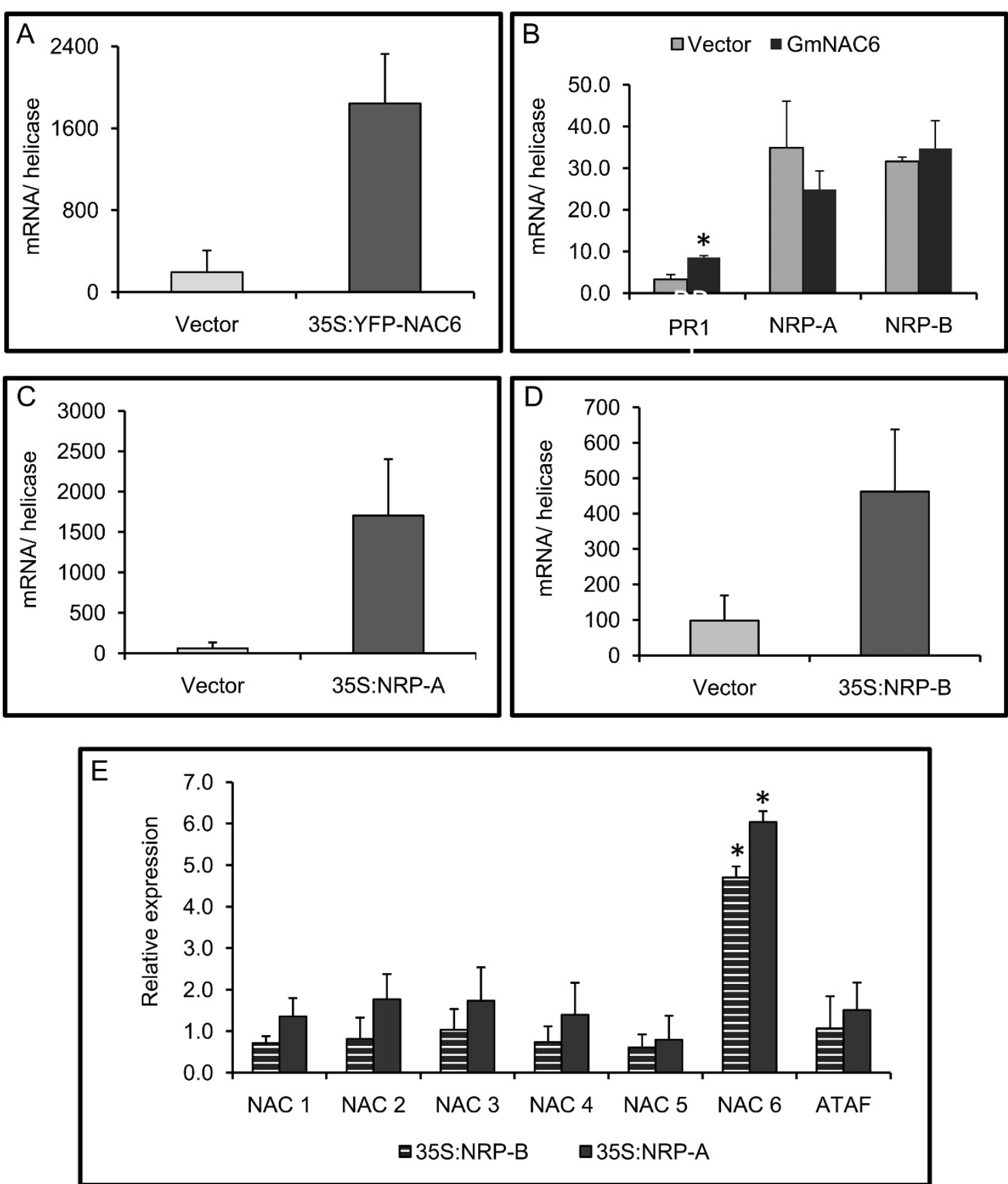

Figure 5 The transient expression of NRP-A and NRP-B induces GmNAC6 expression. A. The expression of GmNAC6 in soybean protoplasts from suspension cells. Soybean protoplasts were electroporated with the 35S::YFP-NAC6 construct or the empty vector, and the expression of GmNAC6 and YFP-GmNAC6 was monitored by qRT-PCR. The values represent the mean \pm SD of three replicates from two independent experiments. B. The transient expression of YFP-GmNAC6 does not impact NRP-A or NRP-B transcript accumulation. Soybean protoplasts were electroporated with the 35S::YFP-NAC6 construct (dark gray) or the empty vector (light gray), and the expression of NRP-A and NRP-B was determined by GRT-PCR. The values represent the mean \pm SD of three replicates from three independent experiments. Asterisks indicate values significantly different from the control treatment ( $p<0.05$, Tukey HSD test). $C$ and D. The expression of NRP-A and NRP-B in soybean protoplasts. Plasmids containing NRP-A (C) or NRP-B (D) expression cassettes were electroporated into soybean protoplasts, and the transient gene expression was monitored by quantitative RT-PCR as in (A). E. The specific induction of GmNAC6 by NRP-A or NRP-B transient expression. Plasmids containing NRP-A (light gray) or NRP-B (dark gray) expression cassettes were electroporated into soybean protoplasts, and the relative expression of NAC genes was monitored by qRT-PCR. The relative quantitation of expression was calculated using $2^{-\Delta \Delta C t}$ method. The values are relative to the control treatment (empty vector), and asterisks indicate those significantly different from the control treatment $(p<0.05$, Tukey HSD test). 


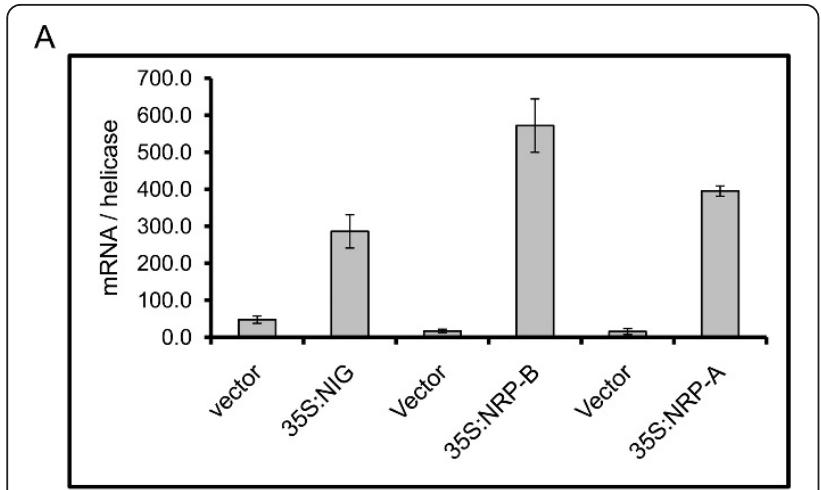

B

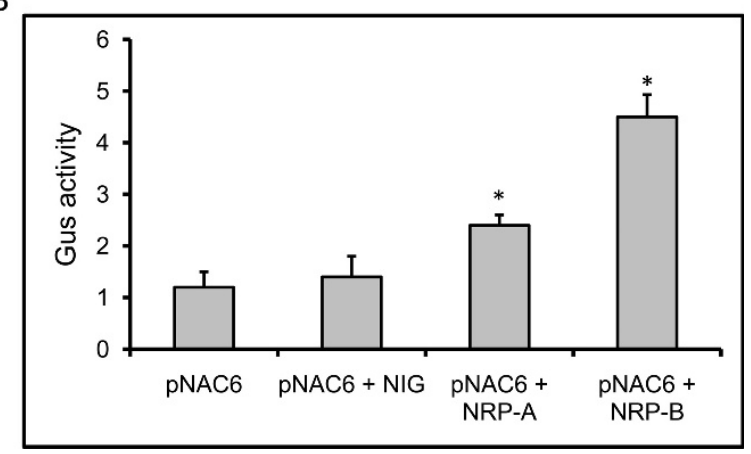

Figure 6 NRP-A and NRP-B induces GmNAC6 promoter activation. A. The transient expression of NIG, NRP-A and NRP-B in soybean protoplasts from suspension cells. Plasmids carrying 35s:: NIG, 35S::NRP-A or 35S::NRP-B expression cassettes or empty vector were electroporated into soybean protoplasts, and the efficiency of transfection was monitored by determining the transient expression (qRT-PCR) $36 \mathrm{~h}$ after electroporation. B. The transient expression of NRP-A and NRP-B in soybean protoplasts activates a GmNAC6 promoter: $\beta$-glucuronidase gene. Soybean protoplasts were coelectroporated with plasmids carrying a GmNAC6-promoter: $\beta$ glucuronidase gene and either 35S::NIG, 355::NRP-A or 35S::NRP-B DNA constructs, or the empty vector (pNAC6). After $36 \mathrm{~h}$, the $\beta$ glucuronidase activity (nmol/min/mg protein) was measured in the total protein extracts of transfected soybean cells. The values represent the mean \pm SD of five replicates from three independent experiments. Asterisks indicate mean values statistically different from the control treatment.

the two stress signals promoted a synergistic accumulation of GmNAC6 transcripts. The synergistic induction of gene expression by the combination of ER stress and osmotic stress inducers is one of the criteria that link target genes to the ER stress- and osmotic stress-integrating pathway. Second, similar to the NRPs, the transient expression of GmNAC6 induced a senescence-like response in tobacco leaves and a cell death response in soybean cells. Lastly, the ectopic expression of $N R P-A$ and $N R P-B$ in soybean cells promoted the activation of the GmNAC6 promoter and the induction of GmNAC6 expression. Collectively, these results position GmNAC6 downstream of the NRPs in the ER stress- and osmotic stress-integrating pathways (Figure 7). However, whether GmNAC6 is linearly coupled to the NRPs in the integrated pathway is still a matter of debate.

NRPs and GmNAC6 were also induced by biotic signals, such as incompatible interactions and CDE treatment, but with different kinetics (Figure 4). While NRPs were rapidly induced by both treatments, increased accumulation of GmNAC6 transcritps occurred with a delayed kinetics. These data were consistent with the delayed induction of GmNAC6 during protoplast preparation, which generates similar signal as the CDE treatment. Therefore, an increased accumulation of NRP-B transcripts preceded the induction of GmNAC6 expression, which supports the argument that GmNAC6 acts downstream of NRPs. This interpretation is further

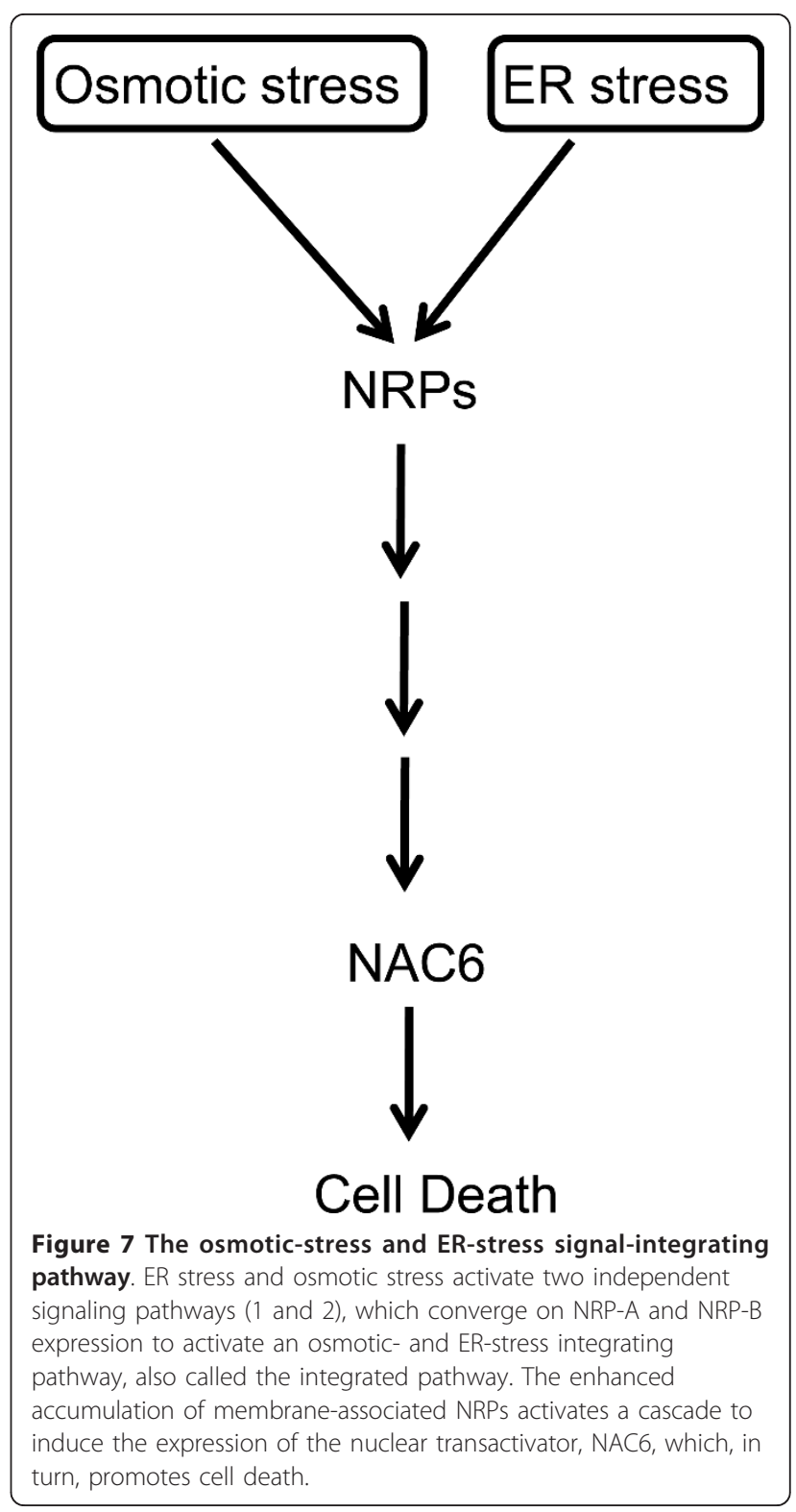


substantiated by the observation that, in our experimental tobacco leaf transient expression system, GmNAC6induced cell death occurred more rapidly than NRPmediated cell death, as it would be expected from effectors acting downstream of NRPs in the cell death signaling pathway.

We found that NRP-B in soybean protoplasts induced GmNAC6 expression and activated GmNAC6 promoter. Whether the NRP-mediated up-regulation of GmNAC6 expression is a direct result of NRPs transactivation of gene expression or a secondary effect of signal transduction mediated by NRP it remains to be determined. Our data favor the latter hypothesis, as we have previously shown that soybean NRPs are localized in the cytoplasm in association with the plasma membrane (13). The Arabidopsis NRP homolog is also a cytosolic protein, but is translocated to the mitochondria under stresses conditions [26]. We don't know whether the soybean NRPs also share a stress-mediated mitochondrial compartmentalization, but we have failed to demonstrate a nuclear localization of NRP-B as it would be expected for a transcriptional activation function. Sequence analysis of 1-kb 5'flanking sequences of GmNAC6 revealed some conserved motifs of most eukaryotic promoters, such as a TATA box (Additional file 5 in pink) and an inverted CCAAT box (in bold), in addition to several potential regulatory elements of plant promoters, potentially involved in response to events of cell death or to osmotic stress and drought. These include an ABA-responsive element, the motif III of rice RAB16b gene1 (in purple), a binding site (in green) of OsBIHD1, a rice BELL homeodomain transcription factor involved in disease resistance, four putative elements (NGATT, in red) for the cytokinin-regulated transcription factor ARR1 and two binding sites (in blue) found in the ERD1 gene, involved in response to dehydration stress and darkinduced senescence. These putative cis-regulatory elements on the GmNAC6 promoter illustrate potential sites for assembly of transcription factors, which might constitute targets of the NRP-mediated stress-induced cell death response.

The evidence that NRPs and GmNAC6 were also induced by biotic signals implies that the NRP-mediated cell death signaling is a general adaptive response of plants. The protective role of the induction of PCD by pathogens during incompatible interactions, a phenomenon well documented in plants, restricts the pathogenic attack to the inoculated cells [27]. The rapid induction of NRP genes by incompatible interactions indicates that the NRP-mediated induction of PCD may be part of the hypersensitive response. Consistent with this hypothesis, the transient expression of GmNAC6 in tobacco leaves promoted the induction of the pathogenesis-related gene 1, PR1 and caused necrotic lesions.
In addition to being induced by ER stress and osmotic stress, NRP-mediated signaling is also induced by drought [18]. These abiotic stress signals induce a shared cell death response through NRPs. While the ER stress branch of the response is distinct from the molecular chaperone-induced branch of UPR [13], we previously showed that the osmotic stress branch of the response may be acid abscisic (ABA)-dependent [16]. In fact, both NRP-B and GmNAC6 are induced by ABA. Furthermore, evidence in the literature has demonstrated an antagonistic effect of ABA on salicylic acid (SA)-dependent defense pathways $[28,29]$. Thus, it may be possible that the activation of NRP-mediated signaling leads to enhanced SA-mediated responses, as shown by the induction of $P R 1$ and hypersensitive response-like phenotypes, and acts antagonistically to suppress ABA-mediated responses. As ABA is a central regulator of plant adaptation to drought $[30,31]$ and plays a crucial role in the regulation of transpirational water loss [32], it would be interesting to investigate whether an inactivation of the NRP-mediated cell death response would promote tolerance to dehydration.

\section{Conclusions}

We have previously demonstrated that the integration of the ER stress and osmotic stress signals into a circuit of cell death occurs through the activation of NRP-mediated signaling pathway $[13,14]$. Expression of NRPs has been shown to be regulated by GmERD15, an ER- and osmotic-stress-induced transcriptional factor [18]. Here, we provided several lines of evidence that link the NAC domain-containing protein GmNAC6 to the NRP-mediated cell death response. Like NRPs, GmNAC6 is synergistically activated by a combination of ER stress and osmotic stress signals and induces a senescence-like response in planta and cell death in soybean protoplasts. NRPs and GmNAC6 are coordinately regulated by a variety of biotic and abiotic stresses but induction of NRPs precedes the up-regulation of GmNAC6. Consistent with this early induction kinetics, expression of NRPs activates the GmNAC6 promoter and induces GmNAC6 expression. Collectively, these results suggest that GmNAC6 may act downstream of NRPs in the ER stress- and osmotic stress-integrating cell death response (Figure 7). This interpretation is further substantiated by the observation that transient expression of GmNAC6 in tobacco leaves induces a more rapid cell death response than that mediated by NRP expression, as it would be expected from effectors acting downstream of NRPs in the cell death signaling pathway. However, whether GmNAC6 is linearly coupled to NRP in the integrated pathway remains to be determined. 


\section{Methods}

\section{Plasmid constructs}

The clone 35S::YFP-NAC6, harboring the NAC6 cDNA fused to yellow fluorescent protein (YFP) under the control of the $35 \mathrm{~S}$ promoter, has previously been described [16]. Similarly, the clones 35S::NRP-A, 35S::NRP-B [13] and 35S::NIG [19], containing the respective cDNAs under the control of the promoter 35S, have already been described.

\section{Plant growth, soybean suspension cells and stress treatments}

Soybean (Glycine max) seeds (cultivar Conquista) were germinated in soil and grown under greenhouse conditions (an average temperature of $21^{\circ} \mathrm{C}$, $\max .31^{\circ} \mathrm{C}$, min. $15^{\circ} \mathrm{C}$ ) under natural light, $70 \%$ relative humidity, and approximately equal day and night length. Two-weeks after germination, the seedlings were transferred to $2 \mathrm{~mL}$ of $10 \%(\mathrm{w} / \mathrm{v})$ polyethylene glycol (PEG; MW 8000, Sigma), $10 \mu \mathrm{g} / \mathrm{mL}$ tunicamycin (Sigma; DMSO, as control) or $50 \mathrm{mM}$ L-azetidine-2-carboxylic acid (AZC, Sigma) solutions. After $8 \mathrm{~h}$ of treatment, the leaves were harvested, immediately frozen in liquid $\mathrm{N}_{2}$ and stored at $-80^{\circ} \mathrm{C}$ until use. Alternatively, the aerial portions of three-week-old plants were excised below the cotyledons and were directly treated with tunicamycin or PEG as described $[13,14]$. Each stress treatment and RNA extraction was replicated in three independent experiments.

For the incompatible interaction experiments, soybean plants in the developmental stage VC [completely expanded unifoliate leaves, as described in the phenologic scale of Fehr and Caviness, [33]] were challenged with Pseudomonas syringae patovar tomato. The bacterial cells were grown at $28^{\circ} \mathrm{C}$ in 523 medium [34]. After centrifugation, the bacterium culture was resuspended in $10 \mathrm{mM}$ $\mathrm{MgCl}_{2}$ to an O.D $600 \mathrm{~nm}$ of 0.2 , corresponding to approximately $1 \times 10^{7}$ cells $/ \mathrm{mL}$ [35]. Soybean leaves were inoculated with the bacterial suspension in the abaxial epidermis of the leaves by using a lightly pressured syringe. At the intervals indicated in the figure legends, the leaf tissue was frozen in liquid nitrogen and stored at $-80^{\circ} \mathrm{C}$ until use.

The treatment of soybean leaves with cell wall-degrading enzymes (CDEs) was performed as previously described [10]. Briefly, soybean leaves at the VC stage [32] were infiltrated with an enzymatic solution $(0.4 \%$ cellulase, $0.2 \%$ macerozyme, $0.6 \%$ mannitol, and $20 \mathrm{mM}$ MES, pH 5.5) or with buffer alone (0.6\% mannitol and $20 \mathrm{mM}$ MES, pH 5.5) as a control. Approximately 3, 10 or $24 \mathrm{~h}$ after inoculation, infiltrated leaves were harvested for analysis.

\section{Real-time RT-PCR analyses}

For quantitative RT-PCR, total RNA was extracted from frozen leaves or cells with TRIzol (Invitrogen), according to the instructions from the manufacturer. The RNA was treated with 2 units of RNase-free DNase (Promega) and was further purified through RNeasy Mini Kit (QIAGEN) columns. First-strand cDNA was synthesized from $4 \mu \mathrm{g}$ of total RNA using oligo-dT(18) and Transcriptase Reversa M-MLV (Invitrogen), according to the manufacturer's instructions.

Real-time RT-PCR reactions were performed as previously described [14]. To confirm the quality and primer specificity, we verified the size of the amplification products after electrophoresis through a $1.5 \%$ agarose gel and analyzed the Tm (melting temperature) of the amplification products by a dissociation curve, performed by the ABI7500 instrument. The primers used are listed in additional file 6 . For the quantitation of the gene expression in the soybean protoplasts and seedlings, we used RNA helicase [14] as the endogenous control gene for data normalization in the real-time RTPCR analysis. For the quantitation of the gene expression in tobacco leaves, we used actin as a control gene [[13]; ABI 158612]. The fold variation, which is based on the comparison of the target gene expression (normalized to the endogenous control) between experimental and control samples, was quantified using the comparative Ct method: $2^{-(\Delta \mathrm{CtTreatment}-\Delta \text { CtControl })}$. The absolute gene expression was quantified using the $2^{-\Delta C T}$ method, and the values were normalized to the endogenous control.

\section{Transient overexpression in Nicotiana tabacum by Agrobacterium infiltration}

Three- to four-week old tobacco leaves were infiltrated with Agrobacterium strain GV3101 pYFP-NAC6, as described [36]. Leaf segments (approximately $0.5 \mathrm{~cm}^{2}$ ) were excised from transfected leaves 3 days post-infiltration, and the protein expression was monitored by confocal microscopy. Leaf segments that displayed the visible appearance of cell death were collected, frozen in liquid nitrogen and stored at $-80^{\circ} \mathrm{C}$ until use.

\section{Determination of chlorophyll content, lipid peroxidation and ion leakage}

The total chlorophyll content was determined spectrophotometrically at 663 and $646 \mathrm{~nm}$ after quantitative extraction from individual leaves with $80 \%(\mathrm{v} / \mathrm{v})$ acetone in the presence of approximately $1 \mathrm{mg}$ of $\mathrm{NaCO}_{3}$ [37]. The extent of lipid peroxidation in the leaves was estimated by measuring the amount of MDA, a decomposition product of the oxidation of polyunsaturated fatty acids. The malondialdehyde (MDA) content was determined by the reaction of thiobarbituric acid (TBA), as described by Hodges et al. [38]. Electolyte leakage was measured from agroinoculated disc leaves as described by Wang et al. [39]. 


\section{Transient expression in protoplasts}

Soybean protoplasts were prepared from 5-day-old subcultures of cotyledon cells of the soybean variety Conquista [40], as previously described [41], with some modifications. Briefly, the protoplasts were isolated five days after subculture by digestion for $3 \mathrm{~h}$, under agitation at $40 \mathrm{rpm}$, with $0.5 \%$ cellulase, $0.5 \%$ macerozyme $\mathrm{R}-10,0.1 \%$ pectolyase Y23, $0.6 \mathrm{M}$ mannitol and $20 \mathrm{mM}$ MES, pH 5.5. The extent of digestion was monitored by examining the cells microscopically every $30 \mathrm{~min}$. After filtration through nylon mesh of $65 \mu \mathrm{m}$, the protoplasts were recovered by centrifugation, resuspended in $2 \mathrm{~mL}$ of 0.6 M mannitol plus $20 \mathrm{mM}$ MES, pH 5.5, separated by centrifugation in a sucrose gradient $(20 \%[\mathrm{w} / \mathrm{v}]$ sucrose, 0.6 M mannitol and $20 \mathrm{mM}$ MES, $\mathrm{pH} 5.5$ ) and diluted with $2 \mathrm{~mL}$ of electroporation buffer $(25 \mathrm{mM}$ HEPES-KOH (pH 7.2), $10 \mathrm{mM} \mathrm{KCl,} 15 \mathrm{mM} \mathrm{MgCl}_{2}$ and $0.6 \mathrm{M}$ mannitol). Transient expression assays were performed by electroporation $(250 \mathrm{~V}, 250 \mu \mathrm{F})$ of $10 \mu \mathrm{g}$ of the expression cassette DNA and $30 \mu \mathrm{g}$ of sheared salmon sperm DNA into $2 \times 10^{5}-5 \times 10^{6}$ protoplasts in a final volume of $0.8 \mathrm{~mL}$. Protoplasts were diluted into 8 $\mathrm{ml}$ of MS medium supplemented with $0.2 \mathrm{mg} / \mathrm{ml} \mathrm{2,4-}$ dichlorophenoxyacetic acid and 0.6 M mannitol, pH 5.5. After $36 \mathrm{~h}$ of incubation in the dark, the protoplasts were washed with $0.6 \mathrm{M}$ mannitol plus $20 \mathrm{mM}$ MES, pH 5.5 and frozen in liquid $\mathrm{N}_{2}$ until use. Protoplasts were also prepared directly from soybean leaves as described [42].

\section{Caspase 3-like activity and in situ labeling of DNA fragmentation (TUNEL)}

Total protein was extracted from soybean cells $36 \mathrm{~h}$ post-electroporation. The caspase 3-like activity was determined using ApoAlert ${ }^{\circledR}$ Caspase 3 Colorimetric Assay Kit (Clontech), according to the manufacturer's instructions, at $\mathrm{pH}$ 7.4. The substrate was DEVD-pNA and the inhibitor of caspase 3-like activity was the synthetic tetrapeptide DEVD-fmk supplied by the kit. Free 3 'OH in the DNA was labeled by the terminal deoxynucleotidyl transferase-mediated dUTP nick end labeling (TUNEL) assay using the ApoAlert DNA Fragmentation Assay Kit (Clontech) as instructed by the manufacturer. Formaldehyde-fixed semi-protoplasted cells that had been transformed with 35S:GmNAC6 were permeabilized with $0.2 \%$ Triton X-100/PBS and TUNEL labeled. Samples were observed with a Zeiss LSM 410 inverted confocal laser scanning microscope fitted with the configuration: excitation at $488 \mathrm{~nm}$ and emission at 515 $\mathrm{nm}$. After being labeled by TUNEL, the slides were rinsed with $\mathrm{PBS}$ for $5 \mathrm{~min}$ at room temperature and counterstained with $10 \mu \mathrm{g} \mathrm{ml}^{-1}$ propidium iodide (PI) containing $0.5 \mu \mathrm{g} \mathrm{ml}^{-1}$ DNase-free RNAse. As positive control, samples were treated with DNase1.

\section{GmNAC6 Promoter Reporter Constructs}

A 1000-bp fragment of 5'-flanking sequences of the GmNAC6 gene http://www.phytozome.net/soybean, relative to the translational initiation codon, was amplified from soybean DNA with the primers promNAC6Fw (5'GAATTCGTCATTTGATTTAAGG-3', to create an EcoRI site, underlined) and pNAC6Rv (5'- AGATCTTCCATGGTTGCCATAT-3', creating the underlined BglII site) and then cloned into the TOPO-pCR4 vector (Invitrogen). The GmNAC6 promoter fragment was then released from TOPO-pCR4 with EcoRI and BglII double digestions and inserted into the same sites of pCAMBIA1381Z to yield pNAC6::GUS (pUFV1255).

\section{GUS activity assays}

The protein extraction and fluorometric assays for GUS activity were performed essentially as described by Jefferson et al. [43] with methylumbelliferone (MU) as a standard. For the standard assay, leaf discs were ground in $0.5 \mathrm{~mL}$ of GUS assay buffer $\left(100 \mathrm{~mm} \mathrm{NaH} \mathrm{PO}_{4}\right.$ .H2O [pH 7.0], $10 \mathrm{mM}$ EDTA, 0.1\% [w/v] sarcosyl, and $0.1 \%[\mathrm{v} / \mathrm{v}]$ Triton $\mathrm{X}-100)$, and $25 \mu \mathrm{L}$ of this extract were mixed with $25 \mu \mathrm{L}$ of GUS assay buffer containing $2 \mathrm{mM}$ of the fluorescent 4-methylumbelliferone $\beta$-D glucuronide (MUG) as a substrate [44]. The mixture was incubated at $37^{\circ} \mathrm{C}$ in the dark for $30 \mathrm{~min}$, and GUS activity was measured using a DYNA Quant 200 Fluorometer.

\section{Additional material}

Additional file 1: Leaf yellowing and necrotic lesions caused by NRP-B expression in tobacco leaves. Leaf sectors were infiltrated with the indicated Agro-inoculum and photographs were taken at 8 days (8d), 10 days (10d) and 11 days (11d) after Agroinoculation. Intense chlorosis was first detected at 8 days post-Agro-infiltration.

Additional file 2: Membrane ion leakage of NRP-B (A) and GmNAC6 (B) Agroinfiltrated leaf sectors. Leaf sectors were infiltrated with the indicated Agroinoculum and ion leakage was measured from leaf discs harvested at 8 days (NRP-B) and 5 days (GmNAC6) post-infiltration. LBA is the result of leaf sectors infiltrated with untransformed Agrobacterium tumefaciens strain LBA4404.

Additional file 3: Pseudomonas syringae patovar tomato (Pst) induces a hypersensitive response in soybean. A bacterial suspension of Pst was infiltrated in the abaxial epidermis of soybean leaves. The picture was taken $24 \mathrm{~h}$ after inoculation.

Additional file 4: Kinetics of GmNAC6 and NRP-B induction during protoplasting procedures. Soybean protoplasts were electroporated with the empty vector pMON921 and the expression of endogenous GmNAC6 and NRP-B was monitored by quantitative RT-PCR using helicase as an endogenous control for the indicated times after electroporation.

Additional file 5: Putative cis-regulatory elements on the GmNAC6 promoter region. GmNAC6 sequences extend until the ATG (bold) translational initiation codon of GmNAC6. Numbers indicate the position relative to the translation start codon. Several putative cis-regulatory elements are indicated in colors. These include a putative TATA box (pink), an inverted CAAT box (bold), an ABA-responsive element (in purple), a binding site of OsBIHD1 (in green), four putative elements (NGATT, in red) for the cytokinin-regulated transcription factor ARR1 and 
cis-elements (in blue) involved in response to dehydration stress and dark-induced senescence.

Additional file 6: Primers used for expression analysis by real time RT-PCR. The table displays the sequence of the primers used for expression analysis of the indicated genes. The access numbers for the genes are also informed.

\section{Acknowledgements}

We thank Prof. Chris Hawes for the 35S-YFP-casseteA-Nos-pCAMBIA1300 binary vector, Prof. Claudine M. Carvalho for technical assistance with the confocal microscopy and Prof. Luciano G. Fietto for critically reading the manuscript. This research was supported by the Brazilian Government Agencies CNPq grants 559602/2009-0, 573600/2008-2 and 470878/2006-1 (to E.P.B.F.) as well as by a FAPEMIG grant, CBB-APQ-00070-09, and a FINEP grant, 01.09.0625.00 (to E.P.B.F.). J.A.S.A.F. and G.L.P. were supported by a CAPES graduate fellowship, and P.A.B.R. was supported by a CNPq graduate fellowship.

\section{Author details}

'Departamento de Bioquímica e Biologia Molecular/BIOAGRO, Universidade Federal de Viçosa, 36570.000, Viçosa, Minas Gerais, Brazil. ${ }^{2}$ National Institute of Science and Technology in Plant-Pest Interactions. Universidade Federal de Viçosa, 36570.000, Viçosa, Minas Gerais, Brazil.

\section{Authors' contributions}

JAQA carried out the experiments, the statistical analysis of the data and drafted the manuscript. MTBR and PABR assisted directly the qRT-PCR assays and the caspase 3-like activity experiment.GLR assisted the Agro-infiltration experiments. GCM assisted directly the TUNEL assay and ion leakage assay. EPBF designed the experiments and edited the manuscript. All authors have read and approved the manuscript.

Received: 17 March 2011 Accepted: 26 September 2011 Published: 26 September 2011

\section{References}

1. Denekamp M, Smeekens SC: Integration of wounding and osmotic stress signals determines the expression of the AtMYB102 transcription factor gene. Plant Physiol 2003, 132:1415-1423.

2. Kreps JA, Wu YJ, Chang HS, Zhu T, Wang X, Harper JF: Transcriptome changes for Arabidopsis in response to salt, osmotic, and cold stress. Plant Physiol 2002, 130:2129-2141.

3. Seki M, Narusaka M, Ishida J, Nanjo T, Fujita M, Oono Y, Kamiya A, Nakajima M, Enju A, Sakurai T, Satou M, Akiyama K, Taji T, YamaguchiShinozaki K, Carninci P, Kawai J, Hayashizaki Y, Shinozaki K: Monitoring the expression profiles of 7000 Arabidopsis genes under drought, cold and high-salinity stresses using a full-length cDNA microarray. Plant J 2002, 31:279-292.

4. Chinchilla D, Shan L, He P, de Vries S, Kemmerling B: One for all: the receptor-associated kinase BAK1. Trends Plant Sci 2009, 14:535-541.

5. Mauch-Mani B, Mauch F: The role of abscisic acid in plant-pathogen interactions. Curr Opin Plant Biol 2005, 8:1-6.

6. Santos AA, Lopes KV, Apfata JA, Fontes EPF: NSP-interacting kinase, NIK: a transducer of plant defence signalling. J Exp Bot 2010, 61:3839-3845.

7. Liu JX, Howell SH: Endoplasmic reticulum protein quality control and its relationship to environmental stress responses in plants. Plant Cell 2010, 22:2930-2942.

8. Urade R: The endoplasmic reticulum stress signaling pathways in plants. Biofactors 2009, 35:326-331.

9. Malhotra JD, Kaufman RJ: The endoplasmic reticulum and the unfolded protein response. Semin Cell Dev Biol 2007, 18:716-731.

10. Jelitto-Van Dooren EP, Vidal S, Denecke J: Anticipating endoplasmic reticulum stress: a novel early response before pathogenesis-related gene induction. Plant Cell 1999, 11:1935-1944.

11. Wang D, Weaver ND, Kesarwani M, Dong $X$ : Induction of protein secretory pathway is required for systemic acquired resistance. Science 2005, 308:1036-1040.
12. Zhang K, Kaufman RJ: From endoplasmic-reticulum stress to the inflammatory response. Nature 2008, 454:455-462.

13. Costa MDL, Reis PAB, Valente MAS, Irsigler AST, Carvalho CM, Loureiro ME, Aragão FJL, Boston RS, Fietto LG, Fontes EPB: A new branch of endoplasmic reticulum-stress signaling and the osmotic signal converge on plant specific asparagine-rich proteins to promote cell death. $J$ Biol Chem 2008, 283:20209-20219.

14. Irsigler AST, Costa MDL, Zhang P, Braga PA, Dewey R, Boston RS, Fontes EPB: Expression profiling on soybean leaves reveals integration of ER and osmotic-stress pathways. BMC Genomics 2007, 8:431.

15. Nuruzzaman M, Manimekalai R, Sharoni AM, Satoh K, Kondoh H, Ooka H, Kikuchi S: Genome-wide analysis of NAC transcription factor family in rice. Gene 2010, 465:30-44.

16. Pinheiro GL, Marques CS, Costa MDBL, Reis PAB, Alves MS, Carvalho CM, Fietto LG, Fontes EPB: Complete inventory of soybean NAC transcription factors: Sequence conservation and expression analysis uncover their distinct roles in stress response. Gene 2009, 444:10-23.

17. Wertz IE, Hanley MR: Diverse molecular provocation of programmed cell death. Trend Biochem Sci 1996, 21:359-364.

18. Alves MS, Reis PAB, Dadalto SP, Faria JAQA, Fontes EPB, Fietto LG: A Novel transcription factor, early responsive to dehydration 15 , connects $E R$ stress with an osmotic stress-induced cell death signal. J Biol Chem 2011, 286:20020-20030, 19.

19. Carvalho CM, Fontenelle MR, Florentino LH, Santos AA, Zerbini FM, Fontes EPB: A novel nucleocytoplasmic traffic GTPase identified as a functional target of the bipartite geminivirus nuclear shuttle protein. Plant J 2008, 55:869-880.

20. Dhindsa RS, Plumb-Dhindsa P, Thorpe TA: Leaf senescence: correlated with increased levels of membrane permeability and lipid peroxidation and decreased levels of superoxide dismutase and catalase. J Exp Bot 1981, 32:93-101.

21. Ueda T, Seo S, Ohashi Y, Hashimoto J: Circadian and senescenceenhanced expression of a tobacco cysteine protease gene. Plant Mol Biol 2000, 44:649-657.

22. Van Loon LC, Rep M, Pieterse CMJ: Significance of inducible defenserelated proteins in infected plants. Ann Rev Phytopathol 2006, 44:135-162.

23. Ludwig AA, Tenhaken R: A new cell wall located $\mathrm{N}$-rich protein is strongly induced during the hypersensitive response in Glycine max L. Eur J Plant Pathol 2001, 107:323-336

24. Valente MAS, Faria JAQA, Ramos JRLS, Reis PAB, Pinheiro GL, Piovesan ND, Morais AT, Menezes CC, Cano MAO, Fietto LG, Loureiro ME, Aragão FJL, Fontes EPB: The ER luminal binding protein (BiP) mediates an increase in drought tolerance in soybean and delays drought-induced leaf senescence in soybean and tobacco. J Exp Bot 2009, 60:533-546.

25. Vidal S, Eriksson ARB, Montesano M, Denecke J, Palva ET: Cell walldegrading enzymes from Erwinia carotovora cooperate in the salicylic acid-independent induction of a plant defense response. Mol PlantMicrobe Interact 1998, 11:23-32.

26. Hoepflinger MC, Pieslinger AM, Tenhaken R: Investigations on N-rich protein (NRP) of Arabidopsis thaliana under different stress conditions. Plant Physiol Biochem 2011, 49:293-302, 27

27. Nimchuk Z, Eulgem T, Holt BF, Dangl JL: Recognition and response in the plant immune system. Annu Rev Genet 2003, 37:579-609.

28. Kariola T, Brader G, Helenius E, Li لـ Heino P, Palva ET: EARLY RESPONSIVE TO DEHYDRATION 15, a Negative Regulator of Abscisic Acid Responses in Arabidopsis. Plant Physiol 2006, 142:1559-1573.

29. Mohr PG, Cahill DM: Abscisic acid influences the susceptibility of Arabidopsis thaliana to Pseudomonas syringae pv. tomato and Peronospora parasitica. Funct Plant Biol 2003, 30:461-469.

30. Yamaguchi-Shinozaki K, Shinozaki K: Transcriptional regulatory networks in cellular responses and tolerance to dehydration and cold stresses. Annu Rev Plant Biol 2006, 57:781-803.

31. Zhu JK: Salt and drought stress signal transduction in plants. Annu Rev Plant Biol 2002, 53:247-273.

32. Schroeder Jl, Allen GJ, Hugouvieux V, Kwak JM, Waner D: Guard cell signal transduction. Annu Rev Plant Physiol Plant Mol Biol 2001, 52:627-658.

33. Fehr WR, Caviness CE: Stages of soybean development. Ames: lowa State University of Science and Technology; 1977, 11.

34. Kado CJ, Heskett MG: Selective media for isolation of Agrobacterium, Corynebacterium, Erwinia, Pseudomonas and Xanthomonas. Phytopathol 1970, 60:969-976. 
35. Bogdanove AJ, Kim JF, Wei Z, Kolchinsky P, Charkowski AO, Conlin AK, Collmer A, Beer SV: Homology and functional similarity of an hrp-linked pathogenicity locus, dspEF, of Erwinia amylovora and the avirulence locus avrE of Pseudomonas syringae pathovar tomato. Proc Natl Acad Sci USA 1998, 95:1325-1330.

36. Carvalho CM, Santos AA, Pires SR, Rocha SR, Saraiva DI, Joao PB Machado, Eliciane C Mattos, Luciano G Fietto, Elizabeth PB Fontes: Regulated nuclear trafficking of rpL10A mediated by NIK1 represents a defense strategy of plant cells against viruses. PLoS Pathog 2008, 4:e1000247.

37. Lichtenthaler HK: Chlorophylls and carotenoids - pigments of photosynthetic biomemembranes. Meth Enzymol 1987, 148:350-382.

38. Hodges DM, Delong JM, Forney CF, Prange RK: Improving the thiobarbituric acid-reactive-substances assay for estimating lipid peroxidation in plant tissues containing anthocyanin and other interfering compounds. Planta 1993, 207:604-611.

39. Wang S, Narendra S, Fedoroff N: Heterotrimeric G protein signaling in the Arabidopsis unfolded protein response. Proc Natl Acad Sci USA 2007, 104:3817-3822

40. Cascardo JCM, Almeida RS, Buzeli RAA, Carolino SMB, Otoni WC, Fontes EPB: The phosphorylation state and expression of soybean BiP isoforms are differentially regulated following abiotic stresses. $J$ Biol Chem 2000, 275:14494-14500.

41. Fontes EPB, Eagle PA, Sipe PS, Luckow VA, Hanley-Bowdoin L: Interaction between a geminivirus replication protein and origin DNA is essential for viral replication. J Biol Chem 1994, 269:8459-8465.

42. Franceschi VR, Ku MSB, Wittenbach VA: Isolation of Mesophyll and Paraveinal Mesophyll Protoplasts from Soybean Leaves. Plant Sci Lett 1984, 36:181-186.

43. Jefferson RA, Kavanagh TA, Bevan MW: Gus fusions: $\beta$ - glucuronidase as a sensitive and versatile gene fusion marker in higher plants. EMBO J 1987, 6:3901-3907.

44. Freitas RL, Carvalho CM, Fietto LG, Loureiro ME, Almeida AM, Fontes EPB: Distinct repressing modules on the distal region of the SBP2 promoter contribute to its vascular tissue-specific expression in different vegetative organs. Plant Mol Bio 2007, 65:603-614.

doi:10.1186/1471-2229-11-129

Cite this article as: Faria et al:: The NAC domain-containing protein, GmNAC6, is a downstream component of the ER stress- and osmotic stress-induced NRP-mediated cell-death signaling pathway. BMC Plant Biology 2011 11:129.

\section{Submit your next manuscript to BioMed Central and take full advantage of:}

- Convenient online submission

- Thorough peer review

- No space constraints or color figure charges

- Immediate publication on acceptance

- Inclusion in PubMed, CAS, Scopus and Google Scholar

- Research which is freely available for redistribution

Submit your manuscript at www.biomedcentral.com/submit 